\title{
Study of the electronic correlation between a benzene plasma and its synthetized polymer phase at low pressure and continuous voltage
}

Estudo da correlação da fase plasma com a fase polímero formada em descargas de benzeno excitadas por tensão contínua

Ricardo Del Sant ${ }^{1}$

\begin{abstract}
Polymer thin films from electrical discharges of hydrocarbons show great technological interest due to their auspicious applications, notably in the mechanical, microelectronic industry, and preparation of biomaterials. In this work, it was studied the correlation of the plasma phase with the polymer phase, formed in benzene discharges excited by continuous voltage of $1,0 \mathrm{kV}$ under pressures which varied from 0,2 to 1,0 mbar. In this pressure range, the electronic temperature varied from 1,5 to $4,3 \mathrm{eV}$. The polymer phase showed continuous fine film morphology or fine film form with powder, containing $\mathrm{OH}, \mathrm{CH}_{3}$ e $\mathrm{CH}_{2}$ radicals, and the polymer growth rate was between 40 and $160 \AA / m i n$. The thermal diffusivity of these materials was measured between $1,0 \times 10^{-3} \mathrm{~cm}^{2} / \mathrm{s}$ and $2,7 \times 10^{-3} \mathrm{~cm}^{2} / \mathrm{s}$.
\end{abstract}

Keywords: Thin films; Polymer; Plasma.

\section{RESUMO}

Filmes finos poliméricos provenientes de descargas elétricas de hidrocarbonetos apresentam grande interesse tecnológico, em razão de suas auspiciosas aplicações, notadamente na indústria mecânica, microeletrônica e confecção de biomateriais. Neste trabalho estudou-se a correlação da fase plasma com a fase polímero formada, em descargas de benzeno excitadas por tensão contínua de 1,0 kV, sob pressões que variaram de 0,2 a 1,0 mbar. Neste intervalo de pressão a temperatura eletrônica variou de 1,5 a 4,3 eV. A fase polímero apresentou morfologia de filme fino contínuo ou forma de filme fino com pó, contendo radicais $\mathrm{OH}, \mathrm{CH}_{3}$ e $\mathrm{CH}_{2}$, e a taxa de crescimento polimérico ficou compreendida entre 40 a $160 \AA /$ min. A difusividade térmica destes materiais foi medida entre $1,0 \times 10^{-3} \mathrm{~cm}^{2} / \mathrm{s}$ e $2,7 \times 10^{-3} \mathrm{~cm}^{2} / \mathrm{s}$.

Palavras-chave: Filmes finos; Polímero; Plasma.

${ }^{1}$ Universidade Anhanguera - Santo André (SP) - Brasil

Correspondence author: Ricardo Del Sant - Universidade Anhanguera - Av. Dr. Alberto Benedetti, 444, Vila Assunção - CEP 09030-340 - Santo André (SP) - Brasil E-mail: delsant1812@gmail.com

Recebido: 13/03/2017 Aceito: 19/07/2017 


\section{INTRODUCTION}

The growing application of plasma polymerized materials, notably in the optoelectronics, pharmaceuticals, mechanical and electrical industry, besides other applications, given their peculiar physical and chemical properties, motivates the study and experiments regarding the preparation and characterization of these materials ${ }^{(1,2,3,4)}$. Such polymers are obtained by electrical discharges of continuous or variable voltage, applied in organic vapors confined in a plasma reactor and kept under low pressure. During this process, an intense fragmentation and ionization of the monomers takes place, resulting in ionized and neutral species, including free electrons and which, along complex reaction mechanisms, recombine, in touch with a substrate, to give rise to a polymeric product in the form of fine film ${ }^{(5)}$.

In this study it was analyzed the correlation between the electronic temperature of the benzene plasma with its vapor pressure besides the data related to the polymer formed as average growth rate, composition and molecular structure, morphology and thermal diffusivity measurement.

\section{Instruments and experimental procedure}

The reactor used has the shape of a pyrex glass cylindrical tube with $17 \mathrm{~cm}$ in diameter and $40 \mathrm{~cm}$ tall, containing two $7 \mathrm{~cm}$ diameter stainless steel electrodes each, arranged in parallel and separated by a distance of $3 \mathrm{~cm}$. The lower electrode was grounded while the upper one was fed by a generator source at a fixed voltage of $1000 \mathrm{~V}$. A stainless steel bottle of $15 \mathrm{~cm}^{3}$ containing liquid benzene introduces benzene in the form of steam into reactor due to the difference of pressure between the contents. The pressure inside the reactor was controlled by a precision needle valve and measured by a Pirani meter. The pumping system in the reactor was run by two pumps, one diffuser pump model OFJ-25 Tokyo Vacuum Machinery, with a capacity of 320 1/min and water cooled, and another Rotary pump one Edwards model E2M8 of double stage with capacity of $200 \mathrm{l} / \mathrm{min}$, connected to the diffuser bomb and the reactor. To measure the electronic temperature it was used a tungsten retractable Langmuir probe with a tungsten tip of $7,0 \mathrm{~mm}$ in length and $0,2 \mathrm{~mm}$ in diameter, controlled by a drive circuit handled by a computer PC 486, which also stored the data. The scheme of the experimental setup is shown in Figure 1.

The measurement of polymer thickness deposited on glass plate with optical flatness was made from a second glass slide placed on the front blade so as to form a step, whose depth is equal to the thickness of the polymer, having been measured by a Tencor 300 microperfilometer. To determine the polymer molecular structure, the technique used was of the infrared absorption through a spectrometer with Fourier Transform, model PerkinElmer, the polymer being deposited on a flat silicon substrate and optically polished on both sides. The range of radiation was between 500 and $4000 \mathrm{~cm}^{-1}$. In the morphological analysis of the polymer surface, it was used the optical microscopy technique with magnifications of 80 and 500 times on the polymer deposited on glass plate with optical flatness.
The thermal diffusivity of the polymers was measured at the Photoacoustics Laboratory of the Departament of Quantum Electronics of the Physics Institute of Unicamp from two laser sources, one of argon (excitation beam) and another of heliumneon (test beam). Two photodiodes, a shutter and a data acquisition recorder completed the experimental setup for the measurement of thermal diffusivity.

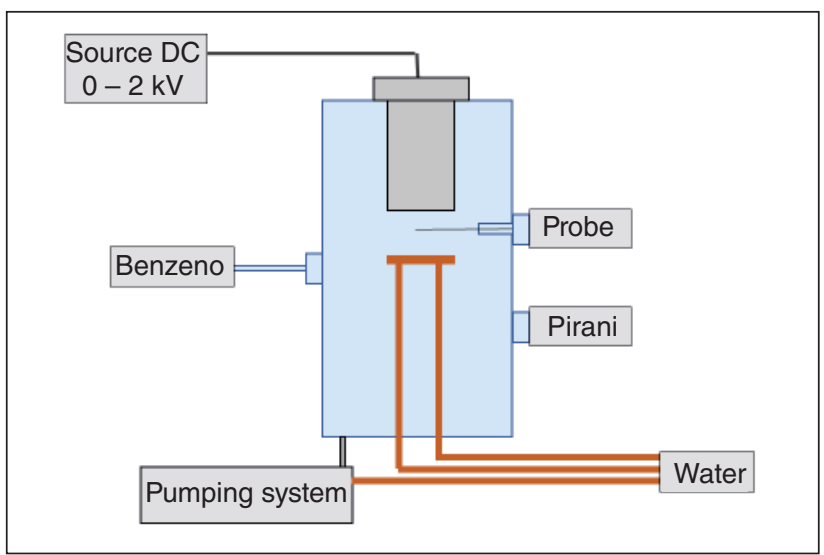

Figure 1: Scheme of the experimental set.

\section{Outcomes and discussion}

The microscopic observation as well as the naked eye revealed two types of morphology of deposited material: continuous fine film and continuous fine film with powder. The first case occurred under pressures from 0,2 to 0,4 mbar while the second occurred under pressures higher than 0,4 mbar. It was also found that increasing the pressure from 0,4 mbar favored the formation of polymeric powder instead of the continuous phase. It should be highlighted that there was polymer deposition on the negative electrode to cover its whole surface, causing sparks in specific points.

It is known that the mean free path of plasma phase constituents decreases with increasing pressure, thereby enhancing nucleation at this stage and reducing interaction with the deposition surface. High reactivity of the monomer and high residence time inside the reactor are also factors that contribute to the formation of powder. Figure 2 shows photo obtained from the formed products, enlarged with optical microscopy.

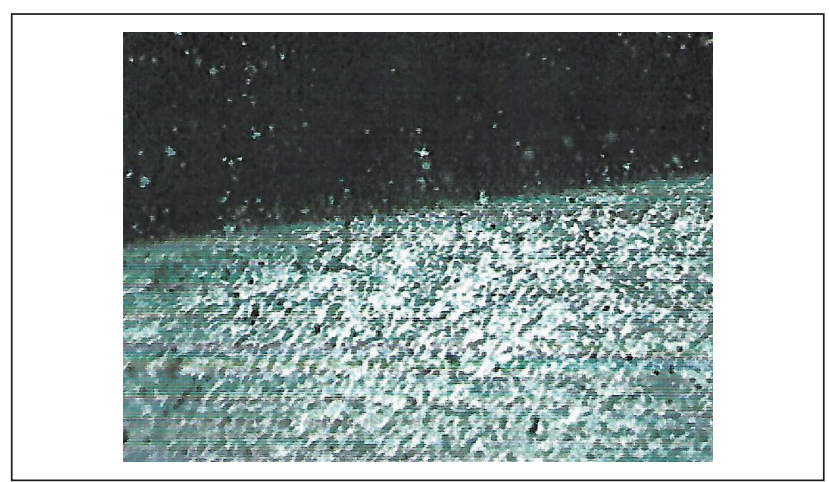

Figure 2: Limit between the fine powder film (light part) and the glass substrate (dark part). Magnification of 80 times. 
Regarding the rate of polymer deposition, there was a marked increase between 0,2 and 0,4 mbar while the polymer formed is in the thin film phase. It is assumed that the increase in pressure is followed by an increase in the formation of free radicals, thus raising the deposition rate. Above 0,4 mbar, however, the deposition rate decreases dramatically due to the presence of the powder formed from this pressure in both the plasma-gas and the gas-surface interface, and which competes against the thin film deposition rate. It is added that part of the polymer powder formed in the plasma-gas environment was expelled by the pumping system.

Figure 3 shows how the average deposition rate varies with the steam benzene pressure.

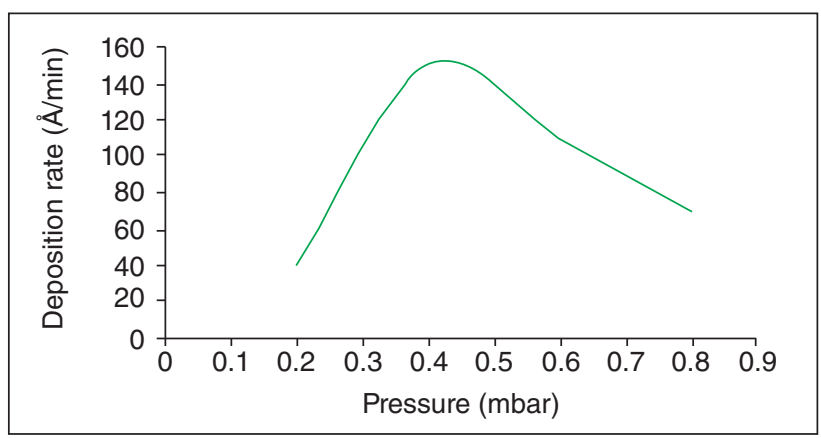

Figure 3: Evolution of the deposition rate as a result of pressure, in a 60-minute deposition.

In three values of pressure, the measurement of the infrared absorption was more intense around $2900 \mathrm{~cm}^{-1}$ due to the presence of symmetrical stretching $\mathrm{C}-\mathrm{H}$ in groups $\mathrm{CH}_{2}$ and $\mathrm{CH}_{3}$ whereas asymmetric deformation $\mathrm{C}-\mathrm{H}$ in groups $\mathrm{CH}_{3}$ was verified around $1400 \mathrm{~cm}^{-1}$. A less pronounced absorption band around $3400 \mathrm{~cm}^{-1}$ under pressure of 0,2 mbar revealed the existence of $\mathrm{OH}$ groups. Unsaturated radicals in the polymer allow the incorporation of other chemical elements, and the presence of oxygen is due to the residues of this gas inside the reactor even at very low pressures, and also to the contamination with the atmospheric air itself, when the deposited material is withdrawn from the reactor ${ }^{(5,6)}$.

Figure 4 shows the infrared absorption spectrum of the polymerized material at 0,4 mbar while Fig. 5 shows the variation

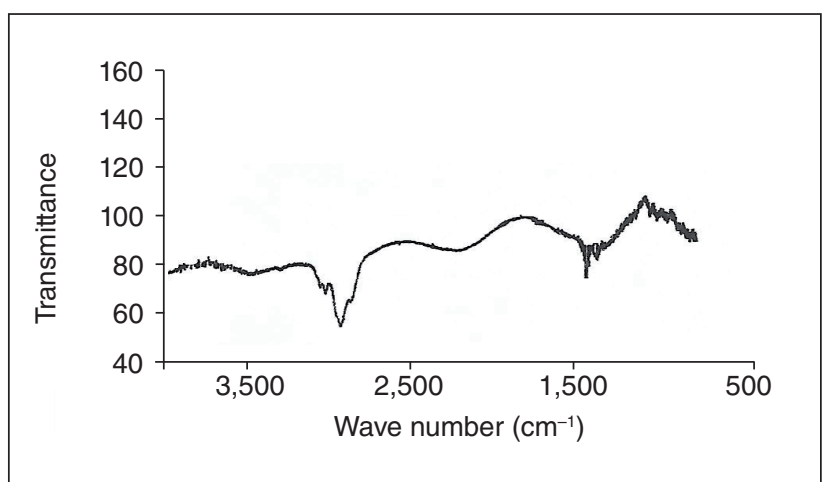

Figure 4: Infrared absorption spectra of the polymer formed at 0,4 mbar and during 60 minutes of deposition. of integrated density of connections $\mathrm{C}-\mathrm{H}$, taken in arbitrary units and measured in the most pronounced absorption band.

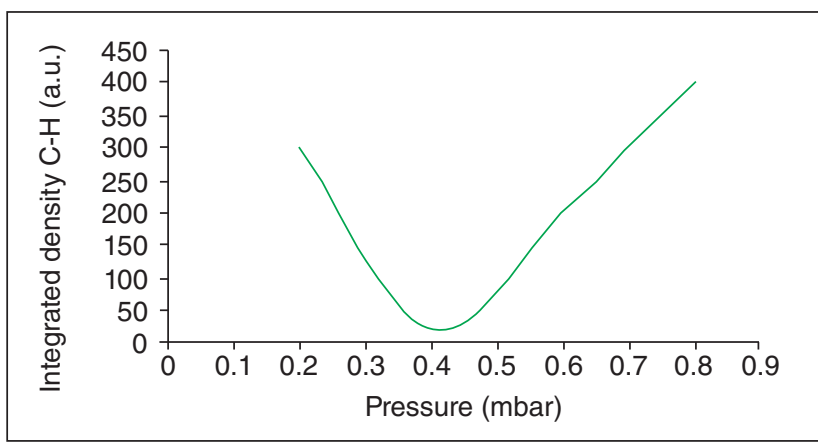

Figure 5: Variation of the integrated density of carbon-hydrogen bonds in $2930 \mathrm{~cm}^{-1}$, containing stretching vibrations, depending on the pressure.

It is seen that, in the interval starting from 0,4 mbar, the density increase integrated in the $\mathrm{C}-\mathrm{H}$ bonds is an indication that the oxygen uptake decreases as the polymer powder is formed. In partially ionized benzene vapor, free electrons are the fastest particles, and the energy they carry can be transferred to other species present in the plasma through collisions, especially in elastic ones, as the electrons are accelerated by the electric field created between the electrodes. A measure of the kinetic energy of the electrons in the plasma is estimated by its average electronic temperature, and Fig. 6 shows how it varied as a result of the vapor pressure during the first minute of discharge.

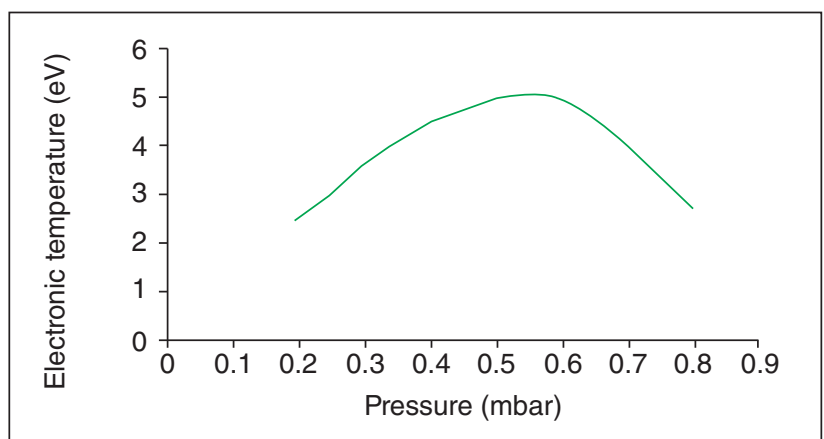

Figure 6: Variation of the average electronic temperature as a result of the vapor pressure, measured in the first minute of DC discharge.

As with the deposition rate, the average electronic temperature increased from 0,2 to 0,4 mbar, decreasing symmetrically from this value. It can be assumed that in the first interval the increase in pressure intensifies the collisional frequency between free electrons and other particles, causing new ionizations and, consequently, more formation of free electrons, some with high energy, which explains the increase of the electronic temperature. From 0,4 mbar, however, the decrease of the free medium path reduces the kinetic energy of the electrons to the point of this effect prevailing over the increase of the collisional frequency, 
justifying the decrease of the average electronic temperature. By setting the vapor pressure, the average electronic temperature was measured at different deposition times, and Fig. 7 shows this evolution at two different pressures.

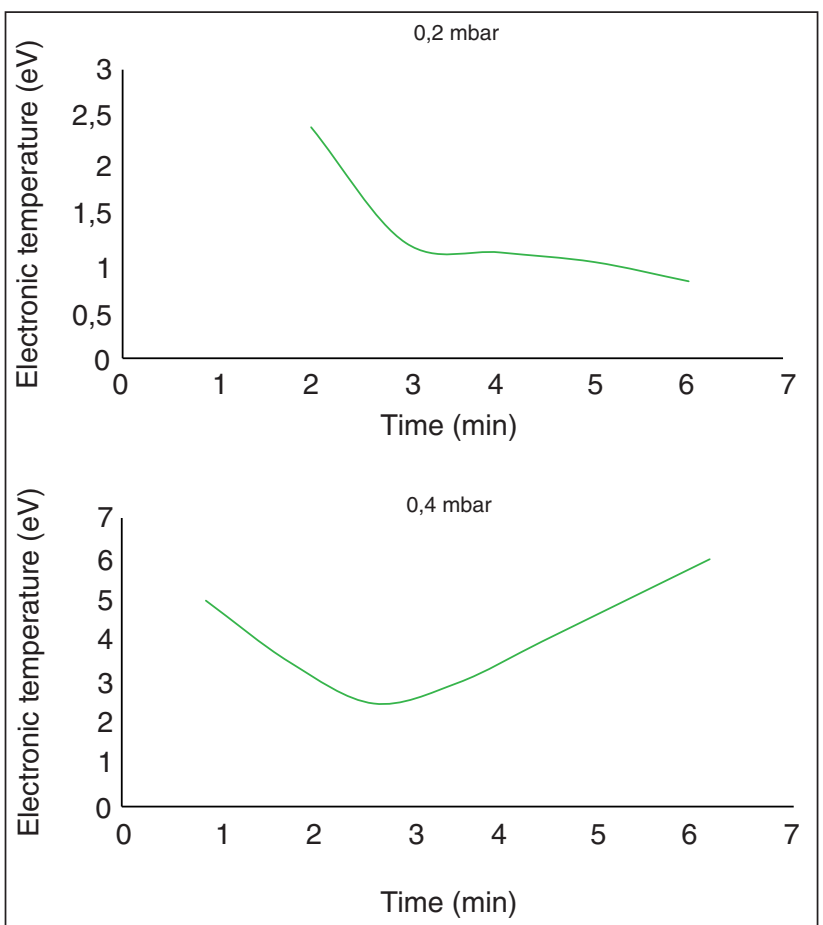

Figure 7: Variation of the electronic temperature depending on the discharge time, in 0,2 mbar and in 0,4 mbar.

In both cases the electronic temperature decreases in the first few minutes of deposition, followed by a tendency to stabilize when the pressure is $0,2 \mathrm{mbar}$, and increase by $0,4 \mathrm{mbar}$. As already pointed out, polymer deposition occurs on the negative electrode, thus creating a dielectric layer that reduces the electric field and the discharge efficiency, as well as the electronic temperature. At 0,4 mbar and due to the sparks that result from the detachment of these dielectric layers, the electronic temperature tends to rise.

The thermal diffusivity was measured in polymers deposited at 0,2 mbar, and the values obtained are in Table 1.

Table 1: Thermal diffusivity values of thin films formed at 0,2 mbar and $60 \mathrm{~min}$ of deposition, corresponding to the electric current and discharge voltage.

\begin{tabular}{cc|c}
\hline Thermal Diffusivity $\left(\mathrm{cm}^{2} / \mathrm{s}\right)$ & $1,02 \times 10^{-3}$ & $2,70 \times 10^{-3}$ \\
\hline Electric current $(\mathrm{mA})$ & 1,0 & 2,0 \\
\hline Final discharge voltage $(\mathrm{V})$ & -1280 & -1935 \\
\hline
\end{tabular}

These results are in agreement with those obtained by photoacoustic technique, which is $1,64 \times 10^{-3} \mathrm{~cm}^{2} / \mathrm{s}^{(6)}$. The change in the thermal diffusivity may be associated to the change in the molecular structure of the polymer, caused by the change of power applied in the discharge.

\section{CONCLUSIONS}

The benzene vapor pressure proved to be a decisive parameter for estimating some quantities, such as the deposition rate of the polymer and the mean electronic temperature of the plasma, the similarity in the variation of these two parameters being evident as a result of the vapor pressure. The increase of the vapor pressure also influences the morphology of the polymer, favoring the formation of powder and inhibiting the deposition of fine film from 0,4 mbar, with consequent decrease of the deposition rate, besides altering the molecular structure of the polymer as it reduces oxygenated radicals such as hydroxyl and carbonyl.

\section{ACKNOWLEDGEMENT}

The author thanks teacher Márcia Navas for the translation of the text into English.

\section{REFERENCES}

1. D'AGOStINO, R., Plasma Deposition, Treatment and Etching of Polymers. Boston: Academic, 1990.

2. YASUDA, H., Plasma Polymerization. Orlando: Academic Press, 1985

3. BIEDERMAN, H.; OSADA, Y., Plasma Polymerization Processes. Plasma Technol., v.1, 1992.

4. RATNER, B. D., New Ideas in Biomaterials Science - a Path to Engineered Biomaterials. J. Biom. Mat. Research 27, 837 (1993).

5. DEL SANT, R., Investigation of the electronic temperature of the plasma phase and study of the morphology, molecular structure and growth of the polymer from a benzene plasma excited by voltage. Masters Dissertation in Applied Physics, UNESP (1999).

6. DEL SANT, R., Influence of vapor pressure on the electronic temperature of a benzene plasma, at the molecular structure, morphology and on the deposition rate of polymer formed, Rev. Cienc. Exatas Tecnol., v.10, n.10, p.36-40, 2015.

7. DEL NERY, S.M. et.al. Thermal diffusivity measurements in $\mathrm{C}_{2} \mathrm{H}_{2}$ plasma polymerized films using photoacoustic techniques, Journal Materials Science Letters, v. 15, p.590-593, 1996. 